\title{
FILOSOFI DAN PENDIDIKAN KARAKTER DALAM TEKS SÊRAT MÉNAK SARÉHAS DUMUGI MÉNAK SORANGAN MELALUI TOKOH AMIR AMBYAH
}

\author{
Amita Hayungningtyas dan Venny Indria Ekowati \\ Universitas Negeri Yogyakarta \\ email: venny@uny.ac.id
}

\begin{abstract}
(Title: Philosophy and Character Education in the Text of "Sêrat Ménak Saréhas Dumugi Ménak Sorangan” through Amir Ambyah's Character). This research is a philological study in the text of Sêrat Ménak Saréhas dumugi Ménak Sorangan. Philosophical studies are in the form of an inventory, description, transliteration, edits and translations of the text of Saréhas dumugi Ménak Sorangan. This study aims to describe character education in the text of Sérat Ménak Saréhas dumugi Ménak Sorangan by using descriptive research methods. The object of the research is the text of Sérat Ménak Saréhas dumugi Ménak Sorangan. The way how to collect data in this research is by using a data card which is further described. There are 5 results of this study. First, the description of the text of Sérat Ménak Saréhas dumugi Ménak Sorangan is still intact and the letters are still clear. Second, by using standard transliteration, the text of Sêrat Ménak Saréhas dumugi Ménak Sorangan which reads Javanese script is changed to Latin script. Third, using standard edition text edits, there are 5 words that get edits, then all changes in edited text are explained in the critics apparatus. Fourth, the results of text translation using bahasa Indonesia and the free translation method are related to the context. Fifth, the contents of the text of Sérat Ménak Saréhas dumugi Ménak Sorangan describe 9 pillars of character education, namely: (1) obedience to God, (2) responsibility, (3) wise, (4) respect and courtesy, (5) generous, love to help, (6) courageous, (7) kind and humble, (8) tolerance, peace and unity, and (9) leadership. The character education is related to the meaning of the illumination symbol wadånå gapurå rênggan in the text of Sérat Ménak Saréhas dumugi Ménak Sorangan.
\end{abstract}

Keywords: Philological study, character education, illumination of wêdånå gapurå rênggan, Sêrat Ménak Saréhas dumugi Ménak Sorangan

\section{PENDAHULUAN}

Peninggalan kebudayaan Jawa di Indonesia merupakan warisan para leluhur. Peninggalan kebudayaan tersebut beraneka macam, salah satunya ialah karya sastra yang berupa naskah lama. Naskah lama berisi tentang informasi hasil budaya pada masa lampau yang ditulis oleh para leluhur. Fathurahman (2017: 22) menyatakan, bahwa naskah ialah dokumen yang di dalamnya terdapat teks tulisan tangan, baik berbahan kertas Eropa, daluwang, daun lontar, kulit kayu, maupun bambu. Naskah di Indonesia sangat banyak jumlahnya dan tersebar di berbagai daerah. Naskah di setiap daerah memilikik karakteristik dan ciri khas yang berbeda. Hal tersebut dilatarbelakangi oleh pengaruh budaya dan bahasa yang digunakan. Wujud perbedaan tersebut merupakan manifestasi dari perkembangan budaya yang berkembang pada masa itu.

Naskah yang terdapat di Yogyakarta dapat ditemukan di tempat-tempat penyimpanan naskah (skriptorarium), seperti Perpustakaan Naskah Museum Sonobudoyo Yogyakarta. Salah satu naskah yang tersimpan di Perpustakaan Naskah Museum Sonobudoyo Yogyakarta adalah Naskah Sêrat Ménak Saréhas dumugi Ménak Sorangan. Naskah Sêrat Ménak Saréhas dumugi Ménak Sorangan selanjutnya disingkat menjadi SMSdMS untuk memudahkan dalam penyebutannya. Naskah SMSdMS tentunya memiliki karakteristik tersendiri dan di dalamnya terdapat informasi hasil budaya pada masa lampau. Sebagai peninggalan yang sangat berharga, masyarakat perlu mempelajari dan memahami isi naskah. 
Hal ini perlu dilakukan agar masyarakat mengetahui dengan jelas cara hidup manusia pada masa lampau.

Naskah SMSdMS merupakan naskah Jawa yang berwujud tembang macapat dan termasuk dalam jenis naskah sastra. Naskah sastra merupakan media pendidikan atau sarana bagi masyarakat menanamkan nilai karakter yang baik. Naskah sastra merupakan hasil budaya yang di dalamnya terdapat berbagai macam pendidikan dan ilmu luhur. Hal tersebut selaras dengan pendapat Nurgiyantoro (2013: 433), bahwa unsur moral dalam karya sastra sering dikaitkan dengan fungsi sastra bagi pembentukan karakter pembaca. Naskah SMSdMS yang merupakan naskah sastra di dalamnya juga memuat pendidikan karakter melalui tokoh utamanya yang bernama Amir Ambyah. Pendidikan karakter tokoh Amir Ambyah dapat dijadikan teladan bagi masyarakat dalam menjalani kehidupan di era globalisasi saat ini.

Naskah $S M S d M S$ ditulis menggunakan aksara Jawa dan berbahasa Jawa. Hal tersebut menandakan bahwa tidak banyak masyarakat yang dapat memahami makna yang terkandung di dalamnya. Untuk dapat mempelajari dan memahami makna yang terkandung dalam naskah SMSdMS, diperlukan metode ilmiah khusus, yakni dengan menggunakan ilmu filologi. Filologi adalah salah satu ilmu yang mempelajari tentang naskah dan teks (Sulistyorini, 2015: 2). Selanjutnya, Saktimulya (2016: 21) menyatakan, bahwa filologi adalah ilmu yang berhubungan dengan studi teks yang dilakukan dalam rangka mengungkapkan hasil budaya yang tersimpan di dalam teks. Pada dasarnya, filologi merupakan pengetahuan yang menginformasikan suatu cerita, baik dalam bentuk tembang maupun cerita narasi. Dapat disimpulkan, untuk dapat mempelajari dan memahami naskah lama, dibutuhkan penelitian filologi.

Naskah SMSdMS yang menjadi objek penelitian filologi merupakan suatu keutuhan yang di dalamnya memuat pesan atau amanat dari pengarangnya. Penelitian ini memfokuskan pada episode 2 naskah $S M S d M S$, karena memuat nilai pendidikan karakter melalui tokoh utamanya, Amir Ambyah. Pendidikan karakter adalah salah satu budi pekerti yang memperhatikan moral. Kata karakter berasal dari bahasa Yunani "charassein" yang artinya mengukir (Johansyah, 2011: 87). Kata karakter selanjutnya berkembang menjadi tanda dan sifat yang berkaitan dengan moral dengan konotasi positif, bukan netral (Judiani, 2010; A. Donni, 2009; Muslich, 2011).

Uraian di atas didukung oleh Setiawati (2017: 348), karakter yaitu nilai-nilai yang unik (mengerti kebaikan, berperilaku baik, dan dampak kebaikan bagi lingkungan) yang diwujudkan dengan tindakan. Pendidikan karakter berkaitan dengan tiga komponen karakter, yaitu pengetahuan moral, perasaan moral, dan perilaku moral (Lickona: 2013; Wibawa: 2013; Widayat: 2018).Ketiga komponen karakter tersebut selanjutnya membentuk moral melalui pendidikan karakter (Praptiwi, 2017:236).

Pengarang naskah SMSdMS tidak hanya menuangkan pesan atau amanat melalui aksara saja, namun juga melalui ilustrasi. Ilustrasi tersebut terletak di awal episode 2, yang berupa iluminasi. Menurut Ekowati, dkk. (2017: 33), iluminasi adalah unsur pendukung keindahan dalam suatu naskah. Iluminasi tidak hanya sekedar untuk hiasan atau unsur keindahan saja, akan tetapi memiliki filosofi atau makna yang tentunya tidak lepas dari isi teks. Iluminasi pada awal episode 2 mengandung makna pendidikan karakter yang sesuai dengan kisah ceritanya.

Menurut Ekowati (2015: 95), kajian terhadap iluminasi naskah Jawa akan mampu mengungkapkan: (1) metode wujud visualisasi naskah yang dapat menggambarkan nilai, norma, aturan hidup, pranata, dan daya cipta masyarakat pemilik manuskrip Jawa-Melayu, (2) proses penciptaan suatu produk seni rupa tradisional, (3) mengungkap faktor-fakto renkulturasi, akulturasi, sinkretisme, dan asimilasi yang disebabkan oleh persilangan budaya asing yang memberikan efek khusus yang tercermin dalam iluminasi, dan (4) ekspresi simbolik dari suatu komunitas masyarakat yang tercermin dalam iluminasi.

Iluminasi pada naskah SMSdMS merupakan hasil kebudayaan fisik yang memiliki keindahan selaras dengan 
budaya Jawa. Naskah diiluminasi dengan indah menggunakan bentuk-bentuk yang beranekaragam. Keindahan dari berbagai jenis motif hias seperti motif tumbuhan, geometris, dan binatang, menjadikan iluminasi pada naskah $S M S d M S$ sangat menarik. Selain itu juga terdapat fungsi yang mengkaji kebermanfaatan iluminasi terhadap naskah dan khalayak, serta makna yang mengkaji seluk beluk terciptanya iluminasi dalam perspektif budaya. Rosalinda (2017: 73) menyatakan, melalui lambang atau simbol, masyarakat percaya pada keagungan atau karakter kuat yang divisualisasikan pada bentuk rupa, karena di dalamnya memuat makna atau filosofi tersendiri.

Namun, iluminasi yang berupa gambar simbol-simbol tersebut tidak banyak diketahui maknanya oleh masyarakat umum. Khususnya iluminasi pada teks $S M S d M S$ episode 2 yang mengandung makna pendidikan karakter melalui tokoh Amir Ambyah. Pesan moral yang terkandung dalam teks SMSdSM dapat digunakan untuk menanamkan nilai-nilai karakter agar terwujud generasi penerus bangsa yang bermoral. Berdasarkan hal tersebut, mendorong peneliti tertarik untuk mengetahui lebih jauh tentang bentuk, fungsi, dan makna pada iluminasi naskah SMSdMS. Selain itu, kondisi perkembangan zaman sekarang, yaitu kurangnya kepedulian serta pengetahuan khalayak umum mengenai warisan budayanya sendiri, khususnya naskah, yang juga menjadi pedoman tentang ajaran serta nilai-nilai luhur. Dengan melihat fenomena tersebut perlu dilakukan penelitian untuk memahami makna filosofis simbol iluminasi naskah SMSdMS.

Selain itu, kondisi naskah SMSdMS masih utuh, keadaan naskahnya masih bagus, teks di dalamnya berupa tulisan tangan yang masih jelas. Meskipun ukuran hurufnya tergolong kecil, namun goresan tintanya masih dapat dibaca dengan jelas. Kondisi kertasnya sudah tidak lagi berwarna putih dan bagian tepinya sobek. Mengingat isi yang terkandung dalam naskah SMSdMS, yakni mengenai pendidikan karakter untuk memperbaiki moral masyarakat saat ini, maka diperlukan penelitian untuk memahami lebih mendalam pesan moral yang ingin disampaikan oleh leluhur. Selain itu, sebagai upaya pelestarian naskah agar tidak rusak, maka diperlukan penelitian lebih mendalam pada naskah SMSdMS.

\section{METODE}

Penelitian ini menggunakan metode penelitian kualitatif dan penelitian filologi. Penelitian kualitatif digunakan untuk menjelaskan tentang pendidikan karakter yang terdapat dalam naskah SMSdMS episode 2 melalui tokoh Amir Ambyah. Penelitian ini juga menggunakan metode penelitian filologi karena data penelitian berupa naskah yang ditulis dengan aksara Jawa. Dengan demikian pendekatan filologi bertujuan untuk menemukan data-data yang akan dianalisis dari pendidikan karakter dalam naskah SMSdMS melalui tokoh Amir Ambyah. Sumber data yang digunakan dalam penelitian ini adalah naskah Sêrat Ménak Saréhas dumugi Ménak Sorangan koleksi museum Sonobudoyo Yogyakarta nomor SK.133.

Pengumpulan data dilakukan dengan langkah penelitian filologi, yaitu dimulai dengan inventarisasi naskah, deskripsi naskah dan teks, transliterasi teks, suntingan teks, dan terjemahan teks. Transliterasi teks dilakukan dengan cara mengganti jenis aksara, yaitu dari aksara Jawa ke aksara Latin. Transliterasi dilakukan dengan tujuan untuk memudahkan dalam membaca teks. Transliterasi dilakukan dengan metode transliterasi standar, yaitu mengganti jenis tulisan yang disesuaikan dengan ejaan yang berlaku (Ejaan yang disempurnakan).

Setelah transliterasi teks, tahap selanjutnya yaitu suntingan teks. Penyuntingan teks dilakukan dengan cara menambah, mengurang, atau mengganti kata-kata di dalam teks secara kontekstual. Kontekstual dalam hal ini disesuaikan dengan isi cerita di dalam teks. Tahap penyuntingan teks mengharuskan peneliti untuk tetap memperhatikan kekhasan yang ada dalam teks. Kekhasan dan keunikan teks tersebut berupa penggunaan kata-kata yang memang berlaku pada jaman penulisan teks.

Selanjutnya yaitu tahap terjemahan teks. Penelitian ini menggunakan metode 
terjemahan harfiah, terjemahan isi, dan terjemahan bebas. Terjemahan dilakukan dengan membuat alih bahasa dari bahasa Jawa diganti menjadi bahasa Indonesia. Kata atau frase yang tidak dapat diterjemahkan ke dalam bahasa Indonesia selanjutnya ditulis dalam catatan terjemahan.

Instrumen yang digunakan dalam penelitian ini berupa kartu data. Kartu data digunakan untuk memudahkan dalam pengelompokan dan analisis data. Analisis data dilakukan dengan analisis deskriptif kualitatif. Cara analisis data dilakukan dengan empat tahapan, yaitu (1) reduksi data, (2) klasifikasi data, (3) display data, dan (4) penafsiran dan interpretasi data (Kaelan, 2005: 69). Reduksi data dilakukan dengan memilah dan memfokuskan data terhadap pilar pendidikan karakter dan mereduksi data yang tidak sesuai dengan pilar pendidikan karakter. Klasifikasi data dilakukan dengan menggolongkan data tentang pilar pendidikan karakter. Display data dilakukan dengan mengelompokkan data yang telah dibagi berdasarkan kategori yang sama. Penafsiran dan interpretasi dilakukan dengan sistematis dan objektif berdasarkan pilar pendidikan karakter. Hasil penafsiran dan interpretasi data selanjutnya diuraikan secara deskriptif.

Pengesahan data dilakukan dengan validitas semantik dan reliabilitas. Validitas semantik yaitu memaknai kata-kata dan kalimat berdasarkan konteksnya. Tahap reliabililtas terbagi menjadi dua, yaitu reliabilitas intrarater dan reliabilitas interrater. Reliabilitas intrarater dilakukan dengan membaca teks berulangulang untuk memperoleh data yang tetap dan konsisten. Reliabilitas interatter dilakukan dengan melakukan verifikasi data kepada ahli filologi.

\section{HASIL DAN PEMBAHASAN \\ Filosofi dan Pendidikan Karakter dalam Teks Sêrat Ménak Saréhas dumugi Ménak Sorangan melalui Tokoh Amir Ambyah}

Penelitian ini membahas pendidikan karakter dalam teks SMSdMS episode 2. Pendidikan karakter yang diperoleh merupakan gambaran dari sifat tokoh utamanya yang bernama Amir Ambyah. Sifat tokoh Amir Ambyah yang berkaitan dengan pendidikan karakter, antara lain: (1) cinta dan taat kepada Allah, (2) tanggungjawab, (3) bijaksana, (4) dermawan dan suka menolong, (5) hormat dan santun, (6) berani, (7) baik dan rendah hati, (8) toleransi, kedamaian, dan kesatuan, dan (9) kepemimpinan. Pendidikan karakter yang tercermin dari sifat tokoh Amir Ambyah dapat dijadikan teladan untuk memperbaiki karakter bangsa saat ini. Sifat tokoh Amir Ambyah yang memuat nilai pendidikan karakter berkaitan dengan pendapatSuherman. MenurutSuherman (dalam Ekowati, dkk., 2017:36), terdapat 9 pilar karakter, yaitu: (1) cinta Tuhan dan kebenaran, (2) bertanggungjawab, disiplin, dan mandiri, (3) amanah, jujur, dan bijaksana, (4) hormat dan santun, (5) dermawan, peduli, dan suka menolong, (6) berani, percaya diri, kreatif, dan pekerja keras, (7) adil dan kepemimpinan, (8) baik dan rendah hati, (9) toleran, cinta damai, dan persatuan. Untuk memudahkan dalam memahami kaitan antara pendidikan karakter dalam diri tokoh Amir Ambyah dengan 9 pilar pendidikan karakter menurut Suherman, maka dibuat tabel seperti berikut. 


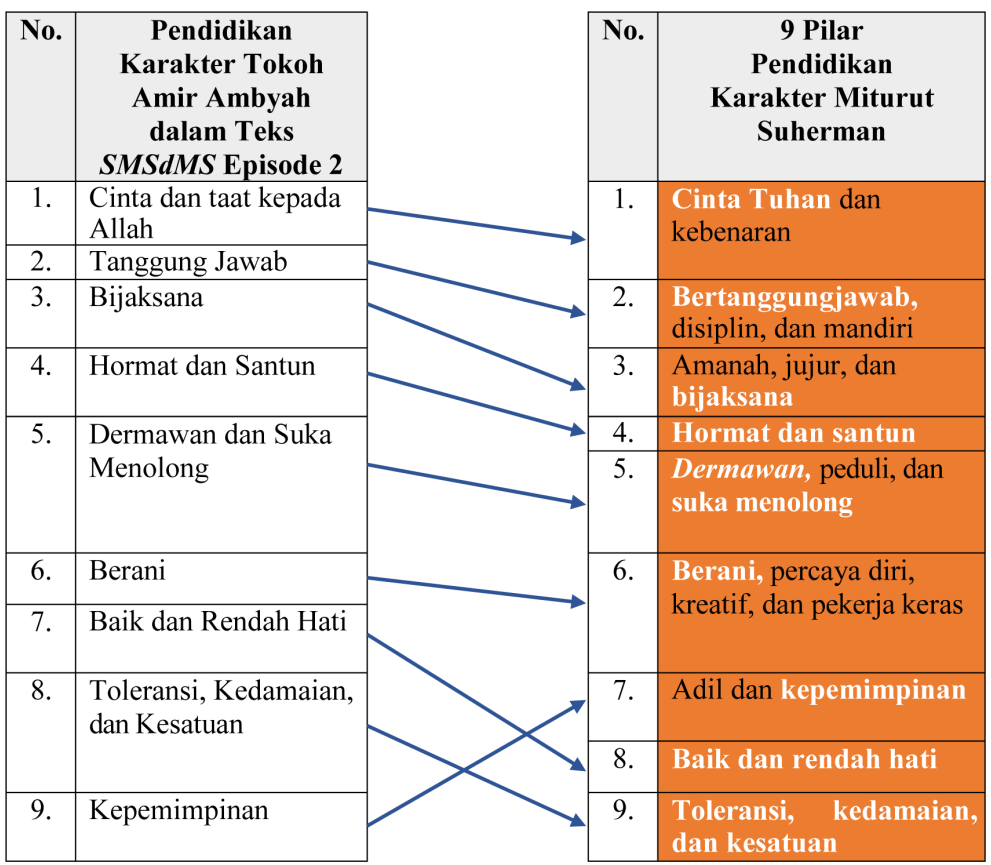

\section{Cinta dan Taat kepada Allah}

Manusia dalam menjalankan

kehidupannya di dunia harus memiliki pedoman agar selamat. Pedoman hidup tersebut akan tercapai jika manusia telah memiliki iman yang merupakan dasar umat beragama. Seperti yang diceritakan dalam naskah SMSdMS, agama yang dicontohkan adalah agama Islam. Helmawati (2017: iii) menyatakan, menurut ajaran Islam, akhlak dalam bahasa Arab berasal dari kata khuluk yang artinya akhlak, karakter, atau perangai. Agama Islam mengajarkan ahklaqul karimah (karakter yang baik) sebagai pedoman hidup. Agama Islam sebagai pedoman hidup tidak akan tercapai dengan baik jika tidak dijalankan dengan karakter yang luhur (Helmawati, 2017: vi).

Nabi Muhammad diutus oleh Allah untuk memperbaiki karakter umat manusia agar memiliki akhlaqul karimah (karakter yang baik). Manusia hidup di dunia sebagai khalifatullah yang berarti pemimpin utusan Allah SWT. Endraswara (2013:43) menyatakan bahwa salah satu karakter kepemimpinan Gajah Mada berdasarkan Kitab Dharma Sastera yaitu rajin sujud, meditasi, atau samadhi. Orang yang rajin sujud berarti rajin ibadah, dan termasuk orang yang religius. Laku sujud atau senantiasa menyembah Allah sangatlah penting karena sebagai pedoman dalam menjalankan hidup.
Karakter yang dimiliki oleh Amir Ambyah dalam teks SMSdMS episode 2 patut untuk diteladani. Sifat Amir Ambyah berkaitan dengan pendidikan karakter religius, yaitu sebagai khalifatullah. Amir Ambyah sebagai khalifatullah diwujudkan dengan bagaimana ia menyebarkan agama Islam. Amir Ambyah dalam menyebarkan agama Islam sesuai dengan petikan teks SMSdMS episode 2 sebagai berikut.

// tibå sangking turånggå pan datan émut / sarwi atinanyå / åpå urip åpå mati / lamun urip nêbutå agamaningwang/-/ (Pucung, 45a)

Terjemahan

Dyan Surya Brongta pun jatuh dari kuda dan tidak menginatapa-apa. Lalu Ambyah bertanya "Kau memilih hidup atau mati? Jika hidup, menyebutlah agamaku!”

Berdasarkan petikan tembang Pucung di atas, dapat dipahami bahwa Amir Ambyah menjalankan kewajibannhya sebagai khalifatullah di dunia, dengan cara mengajak orang yang belum beragama Islam untukmemeluk agama Islam. Dikisahkan, Amir Ambyah hendak menolong kakaknya yang tengah dirampok oleh Surya Brongta. Amir Ambyah berperang melawan Surya Brongta hingga Surya Brongta terjatuh dari kudanya. Melihat kekalahan Surya Brongta, Ambyah segera memerintahkan agar Surya 
Brongta menyebut kalimat syahadat dan memeluk agama Islam. Hal tersebut sesuai dengan pendapat Endraswara (2013: 11), mitologi kepemimpinan Jawa yang sudah mendapat pengaruh Islam, seorang pemimpin sebagai khalifatullah (utusan Allah). Surya Brongta yang diajak oleh Amir Ambyah supaya menganut agama Islam menyetujuinya. Iasenantiasa mengucapkan kalimat syahadat, seperti yang tergambar dalam petikan tembang Pucung di bawah.

// alon muwus Rahadyan Suryå Brongtaku / (kåcå 31) hamba nuwun gêsang / andhèrèk pandukå Amir / linuwaran sampun anêbut sahadat/-/ (Pucung, 46a)

Terjemahan:

Rahadyan Surya Brongta lalu berkata dengan pelan (hal. 31) "Aku ingin hidup dan akan mengikuti Paduka Amir." Ia pun telah menyebut kalimat syahadat.

Petikan tembang Pucung di atas menceritakan kesediaan Surya Brongta untuk memeluk agama Islam dan senantiasa menjalankan syariat Islam. Namun, Ambyah dalam mengajak Surya Brongta dan menyebarkan agama Islam kepada raja-raja lain tentunya membutuhkan ilmu. Ilmu juga menjadi pedoman manusia dalam menjalankan kehidupannya baik di dunia maupun akhirat (Helmawati, 2017: 7). Pernyataan Helmawati sesuai dengan pendapat Samani (2013: 79), bahwa salah satu dasar karakter dalam Islam yaitu haus akan ilmu. Amir Ambyah berguru kepada Pendeta Sidik untuk meningkatkan imannya. Karakter Amir Ambyah dalam mencari ilmu termasuk pilar pendidikan karakter yang dapat diteladani dalam bab ketakwaan kepada Allah SWT. Pernyataan tersebut dikisahkan dalam petikan tembang Kinanthi di bawah.

// mundur radèn kalihipun / praptå ing Mêkah nêgari/ Rahadyan Ambyah winulang / ngaji lan tangkêp ing jurit/ kêlawan sinungan panah / gandéwå awrat nglangkungi /-/ (Kinanthi, 44a)

Terjemahan:

Keduanya lalu undur diri dan pulang. Keduanya sampaidiNegaraMekah. SedangkanRahadyan
Ambyah belajar mengaji dan berlatih dalam peperangan. Ia juga diberi panah gandewa yang sangat berat.

Petikan tembang Kinanthi di atas menceritakan ketika Ambyah berguru kepada Pendeta Sidik. Ambyah dikirim oleh ayahnya untuk mengaji dan menuntut ilmu agama serta ilmu perang. Ambyah berguru ke rumah Pendeta Sidik bersama Tirtanegari dengan diantarkan oleh kedua kakaknya, yakni Raden Janingrat dan Raden Sestraningrat. Manusia hidup di dunia harus senantiasa mencari ilmu dengan berguru kepada orang yang pandai dalam ilmu agama. Tanpa ilmu, manusia tidak memiliki pedoman (Helmawati, 2017: 76). Ajaran agama Islam juga mewajibkan kepada umatnya untuk menuntut ilmu. Bab wajibnya menuntut ilmu juga dipaparkan oleh hadits riwayat Imam Turmudzi, yang terjemahannya sebagai berikut.

"Barang siapa yang menghendaki kehidupan dunia maka wajib baginya memiliki ilmu, dan barang siapa yang menghendaki kehidupan akhirat, maka wajib baginya memiliki ilmu, dan barang siapa menghendaki keduanya maka wajib baginya memiliki ilmu." (HR. ImamTurmuzi).

Kutipan hadits di atas menjelaskan bahwa siapa yang menginginkan kebahagiaan di dunia dan akhirat, maka wajib hukumnya menuntut ilmu. Kutipan hadits di atas juga sesuai dengan pendapat Samani (2013: 84), bahwa dalam menuntut ilmu berdasarkan kutipan ayat Al Quran Surah Fathir yang terjemahannya sebagai berikut.

"Sesungguhnya di antara hamba-hamba Allah yang takut kepada-Nya hanyalah orang-orang yang berilmu." (QS Fathir: 28).

Berdasarkan kutipan ayat Al Quran Surah Fathir di atas, dapat diketahui bahwa orang yang takut kepada Allah SWT pasti mencari ilmu. Kata takut dalam kutipan ayat di atas berarti taat dan takwa kepada Allah SWT. Maka orang yang senantiasa takwa kepada Allah SWT pasti menuntut ilmu untuk bekal di dunia dan akhirat. Untuk mempermudah dalam memahami maksud pernyataan di atas, maka dibuat bagan seperti di bawah. 


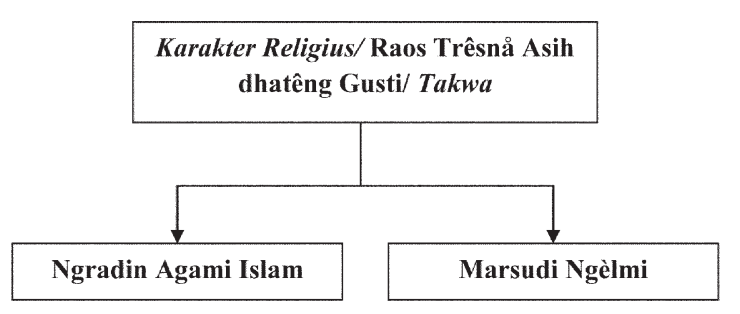

Bagan 6. Wujud karakter Religius

\section{Tanggung Jawab}

Tanggung jawab yaitu wujud kepedulian kepada orang lain. Menurut Lickona (2014: 95), tanggung jawab adalah wujud moralitas terhadap orang lain maupun diri sendiri. Sifat yang termasuk wujud tanggung jawab diantaranya, menjalankan kewajiban, senang menolong, dan senantiasa membuat suasana lebih baik. Seorang pemimpin harus memiliki karakter seperti yang disampaikan oleh Lickona. Ambyah yang memiliki karakter kepemimpinan tentunya memiliki karakter kepemimpinan.

Dikisahkan, Ambyah sudah lama berada di Yahman. Saat sedang tidur, Ambyah mendapat mimpi bahwa negaranya, Mekah tangah dikepung oleh musuh. Ambyah lalu pergi ke Mekah untuk menyelamatkan negaranya. Menurut kutipan tembang Maskumambang, putra Kebar telah menjajah Mekah dengan membuat kerusuhan terhadap prajurit dan rakyat Mekah. Mengetahui hal tersebut, Ambyah lalu segera berperang melawan putra Kebar yang bernama Suma Atmaja. Tindakan Ambyah tersebut sebagai bentuk tanggung jawabnya kepada rakyatnya yang telah dijajah oleh Suma Atmaja. Cerita tersebut seperti kutipan tembang Maskumambang di bawah.

// gyå pinêdhang tumaméng paris tumitis / nêratas ing sirah / tugêl Sumatmåjå lalis/ myarså wadyå bålå Kébar /-/ (Maskumambang, 29)

Terjemahan:

Pedang itupun mampu menembus tameng besinya Suma Atmaja. Ambyah menghantamkan pedangnya ke kepala Suma Atmaja hingga patah dan mati.

Berdasarkan kutipan di atas, dapat diketahui bahwaAmbyah berhasil mengalahkan Suma Atmaja hingga mati. Ambyah mengalahkan Suma Atmaja berdasarkan rasa tanggung jawabnya kepada rakyat Mekah yang telah dirusak oleh Suma Atmaja. Tindakan Ambyah sesuai dengan pernyataan Lombard. Lombard (dalam Endraswara 2013: 114), menyatakan bahwa seorang pemimpin harus memilikisifatadilparamarta, yang berartiwujud tanggung jawab seorang pemimpin kepada bawahannya. Pernyataan tersebut diperkuat oleh pendapat Samani dan Helmawati. Wujud tanggung jawab yaitu senantiasa menjalankan kewajiban dengan senang hati dan tentunya ada konsekuensinya (Samani, 2013; Helmawati, 2017). Selanjutnya, karakter tanggungjawab yang dimiliki Ambyah dikisahkan dalam penggalan tembang di bawah.

// ingkang sêpalih pan sinung / mring Mangkuyudå puniku / wus wêråtå kabèh wadyå ing Mêdayin / sami sukå manahipun / kang sêpalih brånå agong/-/ (Gambuh, 36b)

// kinintunkên Mêkah sampun / sang dipati sarêng ngrungu / apan sangêt sukanirå ingkang galih / déné wau putranipun / kinasih yan mring sang katong /-/ (Gambuh, 37b)

Terjemahan:

Separuhnya diberikan kepada Mangkuyuda. Semuanya sudah dibagi dengan rata. Seluruh prajurit Medayin senang hatinya. Setengah harta agung itu dikirimkan ke Mekah. Sang dipati sangat bahagia hatinya mendengar hal tersebut. Sebab putranya sangat dikasihi oleh sang raja.

Penggalan tembang Gambuh di atas terpisah kalimatnya. Penggalan kalimat tersebut mengisahkan Ambyah memperoleh harta dari Negara Kebar. Ambyah ketika itu masih berada di Medayin, namun tetap mempedulikan keadaan rakyatnya yang berada di Mekah. Wujud rasa tanggung jawab Ambyah kepada rakyatnya yang berada di Mekah berupa mengirimkan harta tersebut ke Mekah. Lombard (dalam Endraswara, 2013: 114) menyatakan, tanggung jawab dapat diwujudkan dengan sifat murah hati. Pernyataan tersebut sesuai dengan tindakan Ambyah yang senantiasa murah hati kepada rakyatnya dengan mengirimkan harta pemberian dari Negara Kebar.

\section{Bijaksana}

Bijaksana adalah dasar dari kebaikan. Bijaksana dapat dilihat dari bagaimana 
cara memilih mana yang baik dan buruk. Karakter bijaksana adalah sifat manusia dalam menentukan keputusan menggunakan akal (Helmawati, 2017: 14). Contoh karakter bijaksana yang dapat diteladani melalui tokoh Amir Ambyah akan dijelaskan dalam penggalan tembang Megatruh sebagai berikut.

// råjå brånå kang sirå jarah rumuhun / sirå balèknå tumuli / mring kadang-kadangirèku / iku pan bakal ubêkti / mring Yahman nêgårå agong/-/ (Megatruh, 2)

Terjemahan:

Kembalikanlah harta benda yang kau rampas kepada saudara- saudaraku itu. Harta itu akan diserahkannya ke negara Yahman sebagai sembah baktinya.

Berdasarkan penggalan pupuh Megatruh di atas, dijelaskan bahwa Ambyah meminta Surya Brongta untuk mengembalikan harta curian yang dirampoknya dari ketiga kakak Ambyah. Hal tersebut dikarenakan harta itu akan dibawanya untuk seserahan sebagai sembah baktinya kepada negara Yahman. Mencuri atau mengambil yang bukan miliknya tergolong karakter yang tidak baik. Ambyah memiliki karakter kepemimpinan karena sifatnya yang bijaksana. Menurut Timotru (2016: 125), pemimpin harus memiliki karakter seperti Dewa Surya, yang artinya bijaksana karena mengajak rakyatnya untuk hidup suci.

Pernyataan tersebut sesuai dengan

karakter kepemimpinan yang dipaparkan oleh Samani. Samani (2013: 94) menyatakan, menurut pupuh Negarakertagama, karakter seorang pemimpin yaitu, (1) wijaya: melaksanakan kewajiban dengan hikmad dan tenang, (2) mantriwira: berani, senantiasa menjadi prajurit untuk negaranya, (3) wicaksanegnanya: senantiasa bijaksana dalam segala tindakan, yang berarti dalam setiap tindakan harus difikirkan terlebih dahulu, (4) mantanggwan: tanggung jawab dan amanah, (5) satyabhakti aprabu: setia terhadap bangsa dan negaranya, (6) wagmiwak: pintar dalam berbicara, (7) sarjjawopasama: rendah hati, tidak sombong, ramah, sopan, dan santun, (8) dhirotsaha: dalam menjalankan pekerjaan selalu sungguh-sungguh dan gigih, (9) tan lalana: selalu ceria tidak terlihat murung atau susah, (10) diwyacitra: demokratis, senang bermusyawarah, (11) tan satrisna: menjaga hawa nafsu, (12) sih samastabhuwana: memliki rasa belas kasih kepada sesama, (13) ginong pratidina: menjalankan yang baik dan meninggalkan yang buruk, (14) sumantri: mengerti kewajibannya, (15) anayaken musuh: gagah perkasa dan tegas.

\section{Hormat dan Santun}

Karakter Ambyah yang terdapat dalam teks SMSdMS episode 2 yaitu karakter hormat dan santun. Menurut Lickona (2014: 95), hormat yaitu karakter untuk mengukur moralitas, artinya dapat menghargai harkat dan martabat orang lain, diri pribadi, dan lingkungan. Pemimpin harus memiliki karakter hormat dan santun. Hal tersebut seperti pendapat Endraswara (2013: 39), bahwa pemimpin harus memiliki karakter wong catur, seperti retna, estri, curiga, dan paksi. Karakter estriyaitu sifat seorang wanita yang sabar, santun, pandai berdiplomasi, dan memiliki budi luhur. Ambyah memiliki karakter kepemimpinan yang senantiasa menghormati orang tuanya. Pernyataan tersebut sesuai dipaparkan dalam penggalan pupuh Gambuh sebagai berikut.

// dèn ngati-atiå kulup / ingkang putrå nêmbah sampun / mêdal sangking ngarsané ingkang sudarmi/ dyan kêkalih gyå lumaku / tanpa rowang mung wong loro /-/ (Gambuh, 5a)

Terjemahan:

Berhati-hatilah, Nak." Sang anak sudah berpamitan dengan hormat lalu pergi dari hadapan ayahnya. Kedua pangeran segera berangkat tanpa ditemani siapapun, hanya berdua saja.

Diceritakan dalam tembang Gambuh alinea 5a bahwa Ambyah hendak melihat kuda yang berada di taman. Konon, kuda tersebut sudah mampu membunuh banyak orang. Ambyah ingin kuda tersebut menjadi kudanya karena tidak ada kuda yang kuat ditunggangi Ambyah. Sebelum pergi ke taman, Ambyah memohon izin kepada ayahnya dengan penuh hormat. Selanjutnya, karakter hormat yang ditemukan pada diri tokoh Ambyah dijelaskan dalam penggalan tembang Maskumambang seperti berikut.

// Dyan Wong Agung myarså råmå gyå tur bêkti/ Tirtånagrå énggal / ngabêkti mring 
sang dipati / tuwinmring Tirtå Diningrat /-/ (Maskumambang, 36)

Terjemahan:

Dyan Wong Agung mengetahui ayahnya menghampirinya, ia lalu segera bersujud menghormati ayahnya. Lalu disusul Tirtanegara yang juga berbakti kepada sang dipati. Begitu pula dengan Tirta Diningrat.

Ambyah adalah anak yang sangat hormat kepada ayahnya, seperti yang tergambar dalam penggalan tembang Maskumambang di atas. Wujud karakter hormat Ambyah kepada ayahnya dilihat dari tindakannya yang senantiasa sujud mencium kaki sang ayah. Tindakan Ambyah tersebut selanjutnya diikuti oleh ketiga kakaknya. Sikap Ambyah yang diteladani oleh orang lain sebagaimana dijelaskan oleh Endraswara. Endraswara (2013: 64) menyatakan, karakter seorang pemimpin harus senantiasa berada di depan. Di depan bermakna seorang pemimpin yang berani dan dapat menjadi teladan untuk orang lain, termasuk pemimpin yang mulia.Karakter hormat umumnya bersamaan dengan karakter sopan dan santun. Berkaitan dengan hal tersebut, Mu'in (2011: 214) mengutarakan, salah satu karakteristik sikap sopan adalah polite, yang artinya etika yang santun untuk menghormati orang lain. Karakter Ambyah dalam menghormati orang lain dibarengi oleh karakter santun. Karakter Ambyah yang senantiasa santun tersebut dipaparkan dalam penggalan tembang Pucung seperti di bawah.

// awilêtan sêmu luhur / jahiting nétrå amanis / mêmak wilis rémanirå / tur ruruh jêtmihkèng trami/ anduplungi tur pisåjå / pêpékå waskithå ngênting /-/ (Pucung, 26a)

Terjemahan:

Pintar dan berbudi luhur, garis matanya manis, rambutnya berwarna hijau tua, ucapannya santun bertata trapsila, ceroboh tidak hatihati dan bisa mengetahui batin orang dengan penuhkebijaksanaan.

Dari penggalan tembang Pucung di atas, dapat diketahui bahwa sejak kecil, Ambyah sudah terlihat santun. Ambyah yang baru berusia satu tahun dan baru saja dapat berbicara, sudah mampu berbicara dengan sopan santun dan memperhatikan tata ktama. Dari cerita di atas, dapat dimengerti bahwa karakter kepemimpinan dalam tokoh Ambyah sudah nampak sejak masih bayi. Orang yang memiliki karakter sopan santun tergolong orang yang memiliki jiwa kepemimpinan. Dasa Raja Dhama mengungkapkan sepuluh kewajiban seorang pemimpin, salah satunya yaitumaddava, yang berarti ramah tamah, sopan santun, dan simpati (Samani, 2013: 97).

\section{Dermawan dan Suka Menolong}

Manusia hidup di dunia harus memiliki karakter baik. Karakter baik menjadi pedoman untuk menjalani hidup yang lebih baik. Menurut Aristoteles (dalam Lickona, 2014: 72), manusia dalam menjalankan kehidupannya harus memperhatikan budi pekerti, artinya memiliki budi yang baik untuk dirinya sendiri, seperti kontrol diri dan untuk orang lain, seperti kedermawanan dan rasa simpati. Manusia yang memiliki rasa simpati terhadap orang lain pasti suka menolong. Manusia yang suka menolong berkaitan dengan karakter dermawan dan rasa simpati. Karakter dermawan dan suka menolong yang ditemukan dalam teks $S M S d M S$ episode 2 melalui tokoh Ambyah seperti penggalan tembang Gambuh berikut.

// nyaoskên kang donyå agung / agé mring wadyå sêdarum/ kang saduman binagé kang råkå sami / kang saduman apan sinung / mring Dyan Tirtånêgaranom /-/ (Gambuh, 16a)

Terjemahan:

Keduaputranya lalu segera menyerahkan harta itu kepada seluruh prajurit. Harta itu diberikan dengan sama banyak oleh kakaknya dan sudah dibagikan dengan rata oleh Dyan Tirtanegara.

Penggalan tembang Gambuh di atas menjelaskan bahwa Ambyah setelah mampu menaklukan kuda di taman, mendapat harta yang banyak. Harta tersebut lalu dibagikan kepada seluruh rakyatnya. Sejak masih berada di taman, Ambyah sudah memiliki keinginan untuk membagikan harta tersebut kepada rakyatnya. Karakter Ambyah yang dermawan selanjutnya dipaparkan dalam penggalan tembang Gambuh di bawah.

// ingkang saduman puniku / Dyan Ambyah bagéanipun/ duk sêmånå anênggih ingkang kawarni / adipati Mêkah sampun / ngumpulkên brånå kang kaot /// (Gambuh, 17a) 
Terjemahan:

Yang dibagikan itu adalah bagiannya DyanAmbyah. Cerita berganti menjadi kisah adipati Mekah. Adipati Mekah mengumpulkan harta benda yang berlebihan untuk diberikan ke negara Yahman.

Berdasarkan penggalan tembang Gambuh di atas, dapat diketahui bahwa Ambyah juga memberikan bagiannya untuk rakyat. Tindakan Ambyah tersebut menandakan bahwa Ambyah memiliki karakter rela berkorban. Karakter Ambyah tersebut sesuai dengan pendapat Samani (2013: 96), salah satu ajaran asta brata yaitu bantala (bumi). Pemimpin harus memiliki karakter seperti bumi yang artinya senantiasa sabar dan dermawan. Selanjutnya, Samani (2013: 96), mengungkapkan, menurut dasa raja dhama, kewajiban pemimpin adalah paricaga, yang berrati rela berkorban untuk rakyatnya. Menurut Lickona (2014: 65), karakter yang baik adalah jujur, adil, bijaksana, disiplin, suka menolong, rasa simpati, kerja sama, berani, dan demokratis.

\section{Karakter Berani}

Pemimpin harus memiliki karakter gagah berani. Pemimpin yang berwibawa pasti disegani oleh bawahannya. Ekowati (2017: 40) mengungkapkan, karakter kepemimpinan yang gagah berani adalah dasar dari karakter yang harus dimiliki pemimpin. Jika pemimpin tidak memiliki karakter berani, maka ia akan diremehkan oleh bawahannya. Cerita dalam teks SMSdMS episode 2 menguraikan bahwaAmbyah sebagai seorang kesatriya, putra Raja Mekah yang memiliki karakter gagah berani seperti dalam kutipan tembang Kinanthi.

Dyan Ambyah / tan pilih papan Dyan Amir / maksih timur aprakoså

/ têtêg tatag Radèn Amir /-/ (Kinanthi, 28)

Terjemahan:

Jika berbicara manisnya bak gula. Semakin dewasa menjadi semakin gagah berani. Keberanian Dyan Ambyah tidak mengenal tempat. Dyan Amir masih muda dan kuat gagah perkasa. Raden Amir sangat teguh dan tidak takut terhadap apapun.
Berdasarkan penggalan tembang Kinanthi di atas, dapat diketahui bahwa Ambyah memiliki karakter gagah berani yang diutarakan oleh pengarangnya. Karakter Ambyahberkaitandengan pendapatEndraswara (2013: 61), salah satu karakter Gajah Mada, pemimpin harus gagah berani, tanggung jawab, dan perkasa dalam segala hal. Pendapat tersebut diperkuat oleh pendapat Helmawati (2017: 14), jika kita memiliki karakter berani, kita dapat menghadapi kesulitan. Selanjutnya, diceritakan dalam penggalan tembang Sinom mengenai karakter berani yang dimiliki Ambyah sebagai berikut.

// lawan tan pangråså sirå / kêlamun sirå wong cilik / iku ratu binêthårå / akèh ratu kang sumiwi / ing Rum Yunan lan Mêsir / Radyan Ambyah nêmbah matur / yèn åmbå sêdyå mêngsah / awuwuhå sèwu nagri / botên ajrih nging ambatan sêdyå mêngsah/-/ (Sinom, 23)

Terjemahan:

Aku hanya orang kecil yang tidak ada apaapanya, apakah mampu melawannya? Itu raja yang sangat agung, banyak dihormati oleh raja- raja di Yunan dan Mesir." Radyan Ambyah berkata dengan sangat hormat "Jika saya bersedia melawannya, meskipun ditambah seribu negara, saya tidak takut menghadapi segala rintangan, itu tidak akan membuat saya pantang mundur untuk melawan musuh."

Menurut penggalan tembang Sinom di atas, Raja Medayin yang bernama Raja Adiwinata memanggil Ambyah agar menghadapnya ke Medayin. Raja Adiwinata mengutus patihnya yang bernama Suradeksana untuk menyampaikan surat dari RajaAdiwinata. Namun, Suradeksana dalam menjalankan perintah Raja Adiwinata tidak sendiri. Ia ditemani oleh 70.000 prajurit. Tirtanegara dan Raja Natadipura menghadang perjalanan Suradeksana beserta prajuritnya. Tirtanegara dan Raja Natadipura menghabisi Suradeksana beserta prajurit karena dianggap telah melanggar aturan. Raja Mekah mengetahui hal tersebut lalu khawatir bagaimana jika Raja Adiwinata murka. Ambyah lalu berkata kepada ayahnya, bahwa dirinya tidak takut meskipun dikepung seribu negara. Karakter Ambyah 
tersebut berkaitan dengan pendapat Lickona (2014: 66), bahwa orang yang memiliki karakter berani, di dalam jiwanya terdapat karakter patriotisme atau jiwa kepahlawanan. Ambyah sebagai pahlawan untuk negaranya dapat dijadikan teladan.

\section{Karakter Baik dan Rendah Hati}

Orang yang baik pasti disenangi banyak orang. Begitu pula pemimpin yang memiliki karakter baik pasti rakyatnya senang dan segan. Karakter baik biasanya dibarengi dengan karakter rendah hati. Orang yang baik pasti tidak sombong dan merendahkan orang lain. Meskipun mampu, namun dirinya tidak menyombongkan kelebihannya. Menurut Ekowati (2017: 38), karakter rendah hati sebagai karakter yang luhur. Ambyah memiliki karakter baik seperti dikisahkan dalam penggalan tembang Kinanthi berikut.

// Bagéndambyah kang linuhung / Kêlånå Jåyådimurti / wong bagus tur wicêksånå / jêtmikå alus sang budi / kang ngluwihi wahyuning Yyang / kang badhé bêrèh påråji /-/ (Kinanthi,13b)

Terjemahan:

Bagenda Ambyah yang luhur, Kelana Jayadimurti yang tampan dan bijaksana, yang berbudi baik bertata trapsila yang melebihi wahyunya Yyang, yang akan memimpin para raja.

Penggalan tembang Kinanthi tersebut menguraikan wujud karakter baik yang dimiliki Ambyah. Karakter baik tersebut diuraikan oleh Ki Suranata dalam suratnya untuk Ambyah. Ki Suranata mengirimkan surat agar Ambyah bersedia menghadap Raja Adiwinata di Medayin. Ki Suranata mengatakan bahwa Ambyah adalah satriya yang memiliki budi baik. Berkaitan dengan hal tersebut, Lickona (2014: 95) mengungkapkan, karakter baik berarti nilai-nilai moral yang berkaitan dengan harga diri. Selanjutnya, karakter andhap asor yang dimiliki Ambyah diuraikan dalam penggalan tembang Maskumambang di bawah.

// pan wus sêdhêng siniwi pun anak Amir / Wong Ménak lon mojar / kang botênbotên ginalih/ mêngkånå sang adipatyå /-/ (Maskumambang, 47)
Terjemahan:

Nak Ambyah juga sudah cukup dihormati." Wong Menak berkata dengan pelan "Jangan mengatakan yang tidak-tidak"

Diceritakan dalam penggalan tembang Maskumambang di atas, Raja Yahman berkata kepada raja Mekah bahwa Ambyah pantas untuk diangkat menjadi raja sebab ia telah disegani oleh banyak rakyat Medayin. Namun, Ambyah berkata kepada raja Yahman agar jangan berbicara demikian. Perkataan Ambyah sebagai wujud karakter rendah hati. Meskipun apa yang disampaikan raja Yahman benar, namun Ambyah tidak ingin menyombongkan hal tersebut. Menurut Samani (2013: 67), pendidikan karakter menurut orang Jawa yaitu rendah hati atau lembah manah, yang berarti tidak sombong.

\section{Toleransi, Kedamaian, dan Kesatuan}

Manusia hidup di dunia tentu harus menjaga persaudaraan, seperti pepatah Jawa "memayu hayuning bebrayan". Orang yang senantiasa menjaga persaudaraan pasti menumbuhkan rasa damai dan tentram. Jika hidupnya tentram kepada sesama, maka akan tumbuh rasa kesatuan. Orang yang senantiasa menjaga persaudaraan pasti memiliki karakter toleransi. Cerita dalam teks SMSdMS episode 2 melalui tokoh Ambyah menguraikan karakter toleransi, seperti dalam penggalan tembang Durma.

// Jayèng Rånå kang asih marang kawulå / yåiku gusti mami / déné ramanirå / Surårêjå ku édan / ratu anakirèng nganjing / sigrå bramantyå / Dyan Suråbau aglis /-/ (Durmå, 18b)

Terjemahan:

"Jayeng Rana yang mengasihiku, dialah gustiku. Sedangkan ayahmu, si Surareja itu dasar, raja anak anjing!' Dyan Surabau sangat marah mendengarnya.

Berdasar penggalan tembang Durma tersebut, diceritakan bahwa raja Kangkan yang bernama Raja Wiryadipura ditangkap oleh Surareja. Namun, menurut Wiryadipura, Surareja telah berbohong karena membiusnya ketika sedang makan. Wiryadipura lalu marah kepada Surareja. Namun, Raja Adiwinata memerintahkan Ambyah untuk menangkap Wiryadipura agar tidak membuat 
kerusuhan di kerajaan. Ambyah berhasil mengalahkan Wiryadipura, namun Ambyah tidak membunuhnya karena rasa belas kasihnya. Ambyah hanya mengikat tangannya Wiryadipura. Putra Surareja yang bernama Surabau lalu bertanya kepada Wiryadipura mengapaWiryadipuratidakmengakuikesaktian ayahnya, namun justru tunduk kepada Ambyah. Wiryadipura lalu mengatakan bahwaAmbyah memiliki rasa belas kasih kepada dirinya. Ungkapan Wiryadipura sesuai dengan karakter toleransi. Karena rasa belas kasihnya kepada Wiryadipura, maka Ambyah tidak membunuh Wiryadipura. Ambyah juga memiliki rasa toleransi dan menjaga persaudaraan dengan tindakannya tersebut. Karakter Ambyah sesuai dengan pendapat Endraswara (2013: 62), bahwa pemimpin harus memiliki karakter dibya cita yang artinya toleransi dan menjaga ketenteraman terhadap sesama.

Karakter Kepemimpinan (Greget, Taat, Bela Negara)

Karakter tokoh Ambyah yang ditemukan dalam teks $S M S d M S$ episode 2 yang paling dominan adalah karakter kepemimpinan. Karakter kepemimpinan terbagi menjadi tiga, yaitu greget, bela negara, dan taat. Menurut Endraswara (2013: 60), berdasarkan karakter Gajah Mada, pemimpin harus memiliki karakter greget. Greget artinya pemimpin harus menjadi motivator untuk bawahannya. Ambyah juga memiliki karakter greget yang dapat menumbuhkan semangat prajuritnya. Hal tersebut seperti dikisahkan dalam penggalan tembang Kinanthi berikut.

// wadyå konên nêngên iku / åjå nå kang ngucap wêdi / dadyå sami julalatan / angambah déså kang mati / Wong Agung Ménak ngandikå / éh tå yayi Ngalap Bani /-/ (Kinanthi, 34b)

Terjemahan:

"Prajurit, perintahkanlah untuk berbelok ke kanan, jangan ada yang merasa takut. Bersigap dan amatilah sekeliling kalian untuk melewati desa yang mati." Wong Agung Menak berkata "Hey, Yayi Ngalap Bani!

Menurut penggalan tembang Kinanthi di atas, dikisahkan Ambyah dan prajuritnya pergi kenegara Medayin untuk menghadap Raja
Adiwinata. Ketika di perjalanan, prajuritnya berhenti di persimpangan jalan. Jalan yang kanan adalah jalan pedesaan yang sudah mati karena binatang buas yang bernama wabru. Wabru tersebut sudah membuat siapa saja yang lewat di situ mati. Ambyah mengetahui hal tersebut lalu memerintahkan prajuritnya untuk melewati jalan sisi kanan. Ambyah menjadi motivator bagi prajuritnya karena prajuritnya diperintahkan untuk tidak takut ketika melewati jalan tersebut

Seluruh prajurit pun berjalan melewati desa yang mati sesuai perintah Ambyah. Sesampainya di desa yang mati tersebut, Ambyah lalu mencari wabru. Wabru itu lalu diremas telinganya hingga mati. Ambyah lalu memerintahkan Surya Brongta untuk menyerahkan wabru tersebut kepada Raja Adiwinata di Medayin. Raja Adiwinata sangat bahagia mendengar berita tersebut. cerita tersebut sesuai dalam penggalan tembang Maskumambang di bawah.

// gyå pinêdhang tumaméng paris tumitis / nêratas ing sirah / tugêl Sumatmåjå lalis/ myarså wadyå bålå Kébar/-/ (Maskumambang, 29)

Terjemahan:

Pedang itupun mampu menembus tameng besinya Suma Atmaja. Ambyah menghantamkan pedangnya ke kepala Suma Atmaja hingga patah danmati.

Dikisahkan dalam penggalan tembang Maskumambang di atas, Ambyah sudah lama berada di Yahman. Ambyah mendapat mimpi bahwa negara Mekah dikepung dan dijajah negara lain. Ambyah lalu pergi ke Mekah untuk menaklukan musuh demi menyelamatkan negaranya. Putra raja Kebar yang bernama Suma Atmaja menyerang Mekah dengan membawa ribuan prajurit. Ambyah lalu perang melawan Suma Atmaja hingga Suma Atmaja tewas. Lalu, prajurit dan saudara-saudara Suma Atmaja yang masih hidup diperintahkan oleh Ambyah untuk memeluk agama Islam. Tindakan Ambyah tersebut sesuai dengan pernyataan Endraswara. Endraswara (2013: 261) menyatakan, pemimpin harus senantiasa setya tuhu kepada negaranya. Karakter setya tuhu kepada negaranya terlihat dari tindakannya dalam menjaga dan melindungi 
negara Mekah dari serangan penjajah. Selain itu, pemimpin harus memiliki rasa tidak rela jika negaranya dirusak dan diserang oleh negara lain. Pemimpin harus menjadi pengayom dan melindungi rakyatnya. Hal itu merupakan bukti ketaatan seorang pemimpin terhadap negaranya. Selanjutnya, dibuat bagan untuk memudahkan dalam memahami karakter kepemimpinan Ambyah dalam teks SMSdMS episode 2 seperti berikut.

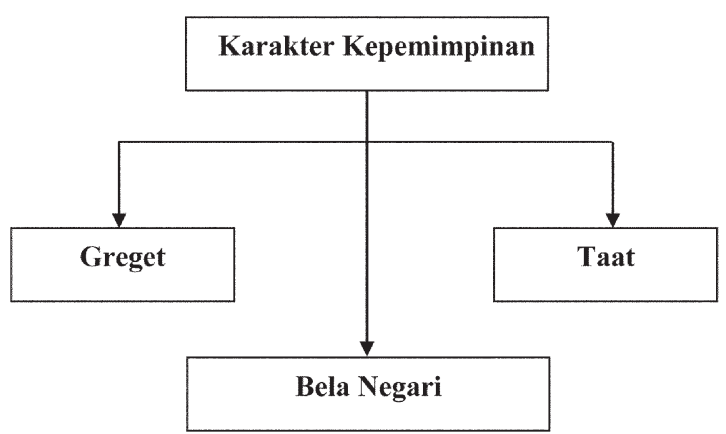

Bagan 8. Karakter Kepemimpinan Amir Ambyah dalam Teks SMSdMS Episode 2
Karakter kepemimpinan dalam diri Ambyah yang sudah dijelaskan di atas, diantaranya pemimpin harus bijaksana, hormat dan santun, dermawan, suka menolong, memiliki rasa asih, berani, dan taat kepada Tuhan (religius). Seluruh karakter tersebut berkaitan dengan wadana gapura rengganyanag ditemukan dalam bagian muka teks SMSdMS episode 2. Simbol-simbol dalam wadana gapura renggan tersebut memiliki makna, yang akan dijelaskan sebagai berikut.

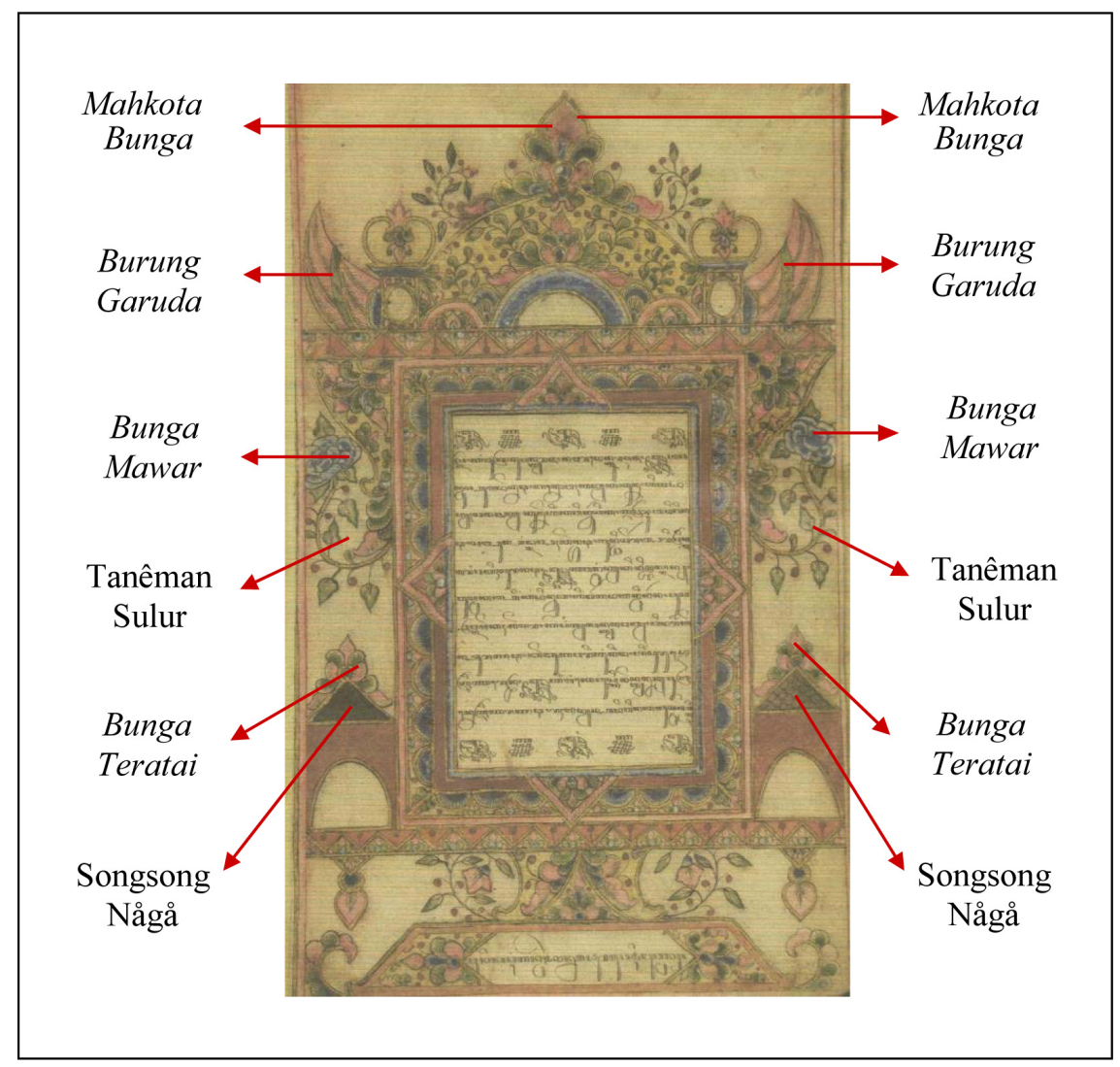

Gambar 11. Iluminasi Wêdånå Gapurå Rênggan Teks SMSdMS Episode 2

Filosofi dan Pendidikan Karakter ... (Amita Hayungningtyas and Venny Indria Ekowati) 
Mahkota bunga, yaitu simbol raja sebagai lambang kepemimpinan. Mahkota bunga juga menjadi lambang tanggung jawab seorang pemimpin kepada rakyatnya. Menurut Rosalinda (dalam Nurhayati 2018: 245), makutha digunakan sebagai lambang kraton mulai dari masuknya agama Islam. Pernyataan tersebut berkaitan dengan teks $S M S d M S$ episode 2 , mengenai isi naskah yanag menceritakan perjuangan Ambyah dalam menyebarkan agama Islam. Selanjutnya, Ekowati (2017: 42) mengungkapkan bahwa mahkota bunga sebagai simbol pemimpin yang berwibawa. Ambyah belum dinobatkan sebagai raja, namun Ambyahsebagai tokoh yang memiliki karakter kepemimpinan.

Burung Garuda, yaitu simbol pemimpin yang agung dan berwibawa. Burung garudasebagai simbol dalam ilmunasi teks $S M S d M S$ episode 2 terwujud dalam bentuk sayap. Sayap digambarkan lengkap satu pasang kiri dan kanan. Pemimpin harus berwibawa sebagai wujud keteguhan dan ketegasan. Burung garudajuga menjadi lambang Tuhan yang Maha Agung. Manusia hidup di dunia harus menghormati Tuhan yang Menguasai Alam Semesta (Nurhayati, 2018: 286). Ambyah sebagai tokoh dalam teks SMSdMS episode 2 senantiasa menghormati Tuhannya dengan cara menyebarkan agama Islam kepada seluruh raja dan kesatriya.

Bunga Mawar, sebagai lambang persaudaraan dan persahabatan. Manusia yang berteman sebagaimana saudara pasti akan saling menghormati. Nurhayati (2018: 288) menyatakan, bunga mawar menggambarkan makna keindahan, keromantisan, rasa cinta, kesucian, kasih sayang, persahabatan, ketertarikan, kesedihan, bahkan juga kematian. Manusia yang memiliki sifat seperti filosofi bunga mawar akan senantiasa menjalankan kehidupannya dalam bermasyarakat sebagaimana pepatah "memayu hayuningbawana."

Naskah SMSdMS episode 2 menceritakan adanya perjanjian antara raja Mekah dengan Ki Suranata. Keduanya berteman sangat akrab sebagaimana seorang saudara. Isi dari teks $S M S d M S$ episode 2 juga mengisahkan perjuangan Ambyah dalam menyebarkan agama Islam dapat membuatnya memiliki banyak teman dan saudara. Selain itu, putra Raja Adiwinata tengah jatuh cinta kepada Ambyah. Cerita tersebut sesuai dengan makna simbol bunga mawar dalam iluminasi teks $S M S d M S$ episode 2.

Bunga Teratai, adalah tanaman yang indah. Bunga teratai mudah tumbuh di mana saja karena benih bunga tertai jika terbang terbawa angin lalu jatuh di suatu tempat yang lembab maka akan tumbuh tunas baru. Bunga teratai memiliki akar yang kuat dan kokoh, maka dapat tumbuh di atas permukaan air dan tidak hanyut. Menurut Nurhayati (2018: 285), filosofi kepemimpinan yang dilambangkan dengan bunga teratai bermakna bahwa seorang pemimpin harus mudah beradaptasi dan tidak takut untuk berkelana kemana saja. Pemimpin harus berani di manapun ia berada.

Cerita dalam teks SMSdMS episode 2, Ambyah sebagai putra raja Mekah memiliki karakter yang berani. Ambyah mampu berkelana dan berhasil menaklukan negara manapun dengan tujuan tidak untuk menjajah negara tersebut, akan tetapi menyebarkanagama Islam. Ambyah dalam menyebarkan agama Islam harus berperang melawan para raja dan kesatriya yang terkenal hebat gagah perkasa. Namun, berkat kegigihannya dan ketaatannya kepada Allah SWT, ia berhasil menaklukan para raja dan kesatriya lalu mengajaknya untuk memeluk agama Islam dengan menjalankan syariat Islam.

Taneman Sulur, menggambarkan lambang kejayaan dan kemuliaan kebudayaan bangsa nusantara yang lestari dan bermanfaat bagi rakyatnya (Nurhayati, 2018: 290-291). Teks SMSdMS episode 2 mengisahkan negara Mekah dan negara Medayin yang makmur dan mulia. Kedua kerajaan tersebut sangat dekat layaknya kerajaan yang bersaudara. Hal tersebut dikarenakan oleh adanya perjanjian antara $\mathrm{Ki}$ Suranata yang menjadi patih Raja Adiwinata di negara Medayin dengan raja yang memimpin negara Mekah. Negara Mekah memiliki rakyat dan prajurit yang hidup berkecukupan. Begitu pula dengan negara Medayin yang sangat luas dan makmur. Raja Adiwinata memiliki banyak prajurit yang sangat menghormatinya. 
Songsong Tunggul Naga, adalah payung yang memiliki motif seperti sisik naga. Iluminasi teks $S M S d M S$ episode 2 terdapat gambar segitiga yang bersisik seperti sisik naga. Gambar tersebut berkaitan dengan isi teks SMSdMS episode 2. Ceritanya, Ambyah diutus oleh Raja Adiwinata untuk menghadapnya di negara Medayin. Ki Suranata lalu memerintahkan putranya yang bernama MangunPukahi untuk menjemput Ambyah di Mekah. Sebelum keberangkatan putranya ke Mekah, Ki Suranata membuatkan payung yang sangat agung. Hanya seorang kesatriyalah yang dapat membuka payung tersebut. Payung tersebut dijuluki dengan Songsong Tunggul Naga.

Cerita tersebut erat kaitannya dengan pendapat Nurhayati. Nurhayati (2018: 248) menyatakan, payung merupakan salah satu lambang kebesaran raja. Sedangkan naga, sebagai lambang pemimpin yang gagah berani dapat memberi pengayoman terhadap rakyatnya (Nurhayati, 2018: 252). Selanjutnya, Seperti telah dikemukakan terdahulu, ular adalah lambang air, sehingga dipilihnya motif ular pada umumnya di Jawa Timur, terkait dengan pentingnya air untuk kehidupan, terutama kehidupan keagamaan. Ambyah memiliki karakter yang gagah berani dan dapat mengayomi prajuritnya. Songsong tunggul naga tersebut kemudian menjadi milik Ambyah sebagai lambang yang dapat menggambarkan karakternya.

\section{SIMPULAN}

Berdasarkan penelitian yang telah dilakukan, maka dapat disimpulkan bahwa terdapat sembilan pendidikan karakter dalam diri tokoh Amir Ambyah yang berkaitan dengan pilar pendidikan karakter menurut Suherman. Pendidikan karakter tersebutjuga erat kaitannya dengan makna filosofis simbol iluminasi pada halaman muka episode 2 teks SMSdMS. Pola iluminasi dalam naskah $S M S d M S$ episode 2 berjenis wadana gapura renggan. Untuk dapat mengetahui makna filosofis setiap unsurnya, dilakukan dengan cara mencocokkan gambar dengan keterangan teks di dalam naskah $S M S d M S$ episode 2. Dengan demikian, fungsi iluminasi bukan hanya sebagai hiasan bingkai halaman naskah semata, namun juga dapat ditelaah lebih dalam mengenai makna filosofis masing-masing unsurnya.

Pendidikan karakter dalam teks SMSdMS episode 2 melalui tokoh Ambyah yang berkaitan dengan makna filosofis wadana gapura akan dijelaskan sebagai berikut. (1) Cinta dan taat kepada Allah SWT difilosofikan dengan makna simbol burung garuda. (2) Karakter tanggung jawab difilosofikan dengan makna simbol mahkota bunga. (3) Karakter bijaksana dilambangkan dengan filosofi simbol songsong tunggul naga. (4) Karakter hormat dan santun dilambangkan dengan filosofi simbol bunga mawar. (5) Karakter dermawan dan suka menolong difilosofikan dengan simbol taneman sulur. (6) Karakter berani dilambangkan dengan filosofi simbol bunga teratai dan songsong tunggul naga. (7) Karakter baik dan rendah hati dilambangkan dengan filosofi simbol bunga mawar. (8) Karakter toleransi, kedamaian, dan kesatuan dilambangkan dengan filosofi simbol bunga mawar. (9) Karakter kepemimpinan (greget, bela negara, dan taat) dilambangkan dengan filosofi simbol mahkota bunga.

\section{DAFTAR PUSTAKA}

Ekowati, V I., dkk. (2017). Pendidikan Karakter Iluminasi Naskah Babad Pecinna. Jurnal Penelitian Humaniora, Vol. 22, No. 1.

Endraswara, S.(2013).Falsafah Kepemimpinan Jawa. Yogyakarta:NaARASI(Anggota IKAPI).

Fathurahman, O. (2017). Filologi Indonesia Teori dan Metode. Jakarta: Kencana.

Helmawati. (2017). Pendidikan Karakter Sehari-Hari. Bandung: PT Remaja Rosdakarya.

Johansyah, J. (2011). Pendidikan Karakter dalam Islam; Kajian dari Aspek Metodologis. Vol. 11. No. 1.

Judiani, S. (2010). Implementasi Pendidikan Karakter di Sekolah Dasar melalui Pengamatan Pelaksanaan Kurikulum. Jurnal Pendidikan dan Kebudayaan Vol. 16 Edisi Khusus III. Balitbang Kementerian Pendidikan Nasional. 
Kaelan. (2005). Metode Penelitian Kualitatif Bidang Filsafat. Yogyakarta: Paradigma.

Koesoema, D. (2009). Pendidikan Karakter di Zaman Keblinger, Mengembangkan Visi Guru sebagai Pelaku Perubahan dan Pendidikan Karakter. No. 80. Jakarta: Grasindo.

Lickona, T. (2014). Pendidikan Karakter Panduan Lengkap Mendidik Siswa Menjadi Pintar dan Baik. Bandung: Nusa Media.

Mu'in, F. (2011). Pendidikan Karakter Konstruksi Teoretik dan Praktik. Yogyakarta: Ar-Ruzz Media.

Muslich, M. (2011). Pendidikan Karakter: Menjawab Tantangan Kritis Multidimensional. No. 71. Jakarta: Bumi Aksara.

Nurgiyantoro, B. (2013). Teori Pengkajian Fiksi. Yogyakarta: Gadjah Mada University Press.

Nurhayati, E. dkk. (2018). Dunia Manuskrip Jawa Teori, Metode, dan Aplikasinya dalam Praktik Pernaskahan Jawa. Yogyakarta: Cantrik Pustaka.

Praptiwi, F.N. (2017). Pendidikan Karakter Tokoh Utama dalam Novel Cahaya Cinta Pesantren Karangan Ira Madan dan Semester Pertama di Malory Towers Karangan Enid Blyton. Jurnal Pendidkan Bahasa dan Sastra. Vol. 1 No. 2 e-ISSN: 2580-9040.
Rosalinda, H. dan Umi K. (2017). Memaknai Bentuk-Bentuk Rupa Lambang Keraton Mangkunegaran. Jurnal Desain No. 4 Vol. 2 Januari 2017: 73-84

Saktimulya, S.R. (2016). Naskah-Naskah Skriptorium Pakualaman. Jakarta:KGP (Kepustakaan Populer Gramedia).

Samani, M. dan Hariyanto. (2013). Pendidikan Karakter. Bandung: PT Remaja Rosdakarya.

Santiko, H. (2015). Ragam Hias Ular-Naga di Tempat Sakral Periode Jawa Timur. AMERTA, Jurnal Penelitian dan Pengembangan Arkeologi Vol. 33 No. 2, Desember 2015: 77-134.

Setiawati, Nanda Ayu. (2017). Pendidikan Karakter sebagai Pilar Pembentukan Karakter Bangsa. Prosiding Seminar Nasional Tahunan Fakultas Ilmu Sosial Universitas Negeri Medan Tahun 2017 Vol. 1 No. 1 2017, Hal. 348-352

Sulistyorini, Dwi. (2015). Filologi Teori dan Penerapannya. Malang: Madani.

Timotiu. (2016). Kepemimpinan dan Kepengikutan: Teori dan Perkembangannya. Yogyakarta: Andi Offset.

Wibawa, S. (2013). Filsafat Moral dalam Serat Centhini melalui Tokoh SheAmongraga Sumbangannya bagi Pendidikan Karakter.

Widayat, A. (2018). Lakon Banjaran Anoman Sajian Ki Timbul Hadiprayitno dalam Perspektif Etika: Relevansinya dengan Pendidikan Karakter. 